\title{
Tribological Assessment of Modified Jatropha Oil with hBN and Graphene Nanoparticles as a New Preference for the Metalworking fluid
}

\author{
Nor Athira Jamaluddin, Norfazillah Talib, Amiril Sahab Abdul Sani
}

\begin{abstract}
Recently, manufacturing industries have concerned about the utilization of mineral-based metalworking fluids because of the numerous deleterious impacts on the health of workers and the environment as well as the shortage of mineral resources. Due to this scenario, the vegetable-based oils have emerged the researchers' attention as a suitable replacement for the mineral based metalworking fluids since it is highly biodegradable, low toxicity and renewable resources. Nevertheless, the main problem of the utilization of the vegetable-based oils is that it shows poorer thermal and oxidative stability. The great development technologies had influenced the application of the nanofluids by adding the nanoparticles additives to the base oil as it gives better physical and properties, thus improved the tribological behavior. This study focuses on developing a new green synthesis and formulation of nanofluids from chemically modified jatropha oil by blending with nanoparticles additives such as hexagonal boron nitride (hBN) and graphene at the minimum concentrations $(0.01,0.025$ and 0.05 wt.\%). The physical testing such as kinematic viscosity, viscosity index and flash point were conducted and compared with commercial synthetic ester (SE). Then, tribological testing was performed by using four ball tribo test and analyses in terms of coefficient of friction, worn surface analysis and surface roughness. From the results, the sample of MJOs had showed an enhancement by providing higher viscosity index. The results demonstrate that $\mathrm{MJOg} 2$ provided the lowest coefficient of friction while MJOh3 and MJOg3 had smoother worn surface as it has lowest value of surface roughness in comparison with others sample. It can be concluded that the MJO samples have high potential substitution to mineral-based oil as a sustainable metalworking fluid in machining processes.
\end{abstract}

Keywords: Vegetable-based oil, Nanofluid, Tribology, Sustainable Metalworking Fluid, Nanoparticle

\section{INTRODUCTION}

Manufacturing industries are mainly involved machining processes at which the use of metalworking fluids (MWFs) was widely applied in order to minimize the friction between

Revised Manuscript Received on February 25, 2020.

* Correspondence Author

Nor Athira Jamaluddin, Faculty of Mechanical and Manufacturing Engineering, Universiti Tun Hussein Onn Malaysia, Batu Pahat, Johor, Malaysia. Email: norathira95@gmail.com

Norfazillah Talib*, Faculty of Mechanical and Manufacturing Engineering, Universiti Tun Hussein Onn Malaysia, Batu Pahat, Johor, Malaysia. Email: fazillah@uthm.edu.my

Amiril Sahab Abdul Sani, Faculty Manufacturing Engineering, Universiti Malaysia Pahang, Pekan, Pahang, Malaysia. Email: amiril@ump.edu.my

(C) The Authors. Published by Blue Eyes Intelligence Engineering and Sciences Publication (BEIESP). This is an open access article under the CC BY-NC-ND license (http://creativecommons.org/licenses/by-nc-nd/4.0/) the workpiece and cutting tool as well as prolonged the wear of the tool. The main conventional MWFs that extensively used in the industries are mineral-based oils derived from crude or petroleum reserves as it offers reasonable price and have excellent technical properties for machining processes. However, mineral based MWFs are low biodegradable, non-renewable resources and high toxicity which can possess a negative effect on the environment such as contaminate soil directly and caused water and air pollution [1]. Moreover, the mineral-based MWFs is associated with increased health risk health of the workers via skin contact and inhalation when exposed to the mists or aerosols of the MWFs [2]. These problems had attracted the attention of researchers to explore the potential candidates by using vegetable oils to shift the use of conventional MWFs. Vegetable oils are preferred as a sustainable substitution because of high biodegradable, low toxicity toward human and environment and comes from renewable resources that be obtained continuously [3]. In addition, vegetable-based oils offer favorable attributes such as higher lubricity, higher viscosity index, higher shear stability, lower volatility and higher load carrying capacity. Nevertheless, the utilization of vegetable oils possesses some limitation because of their poor thermal-oxidative stability properties due to fact that the main component of vegetable oils are triglyceride which consists of free fatty acids (FFA) and glycerol. Most of the vegetables oil contains unsaturated fat which having double bonds between the carbon atom within the fatty acid chain [4]. The excellent biodegradable lubricant can be developed using various method to enhance their properties, for instance, modification through chemical reaction of vegetable-based oils and reformulation of additives [5]. The application of nanofluids are widely spread in lubrication systems where the nanometer size of particles additives are added in base fluids and have anti-friction and anti-wear properties which consequently promotes improvements in tribological and machining performance.

Kashyap and Harsha [6] evaluated the tribological performance of the rapeseed oil that had been chemically altered and blended with ceria $\left(\mathrm{CeO}_{2}\right)$ and copper oxide $(\mathrm{CuO})$ nanoparticles at concentration of 0.1 to $1.0 \mathrm{wt}$ \% through four ball test. It can be stated that the lowest of coefficient of friction was obtained by the $\mathrm{CeO} 2$ and $\mathrm{CuO}$ nanofluid at an optimum concentration of nanoparticles. The mechanism of nanoparticles addivites was acts as nanobearings which changing the configuration of the surface contact from sliding to rolling, consequently reduces the coefficient of friction. 
It also argued that at the lowest concentration of nanoparticles the contribution of nanoparticles was considered not sufficient to facilitate the rolling motion as well as higher concentration of nanoparticle which more contributed on high contact configuration reverts back.

A recent study from Gupta et al. [7] proved that inclusion of nanoparticles additives into base oil had better in machining performance due to their good tribological and cooling properties. In their study, turning operation of Inconel-800 Alloy was conducted by applying minimum quantity lubricant (MQL) system using sunflower oil as base oil and mixed with three types of nanoparticles additives which are molybdenum disulfide $\left(\mathrm{MoS}_{2}\right)$, graphite and aluminium dioxide $\left(\mathrm{Al}_{2} \mathrm{O}_{3}\right)$ at concentration of $3 \%$ respectively. The result reveals that graphite nanofluids provided better machining performance as it provided lowest cutting force at various condition of the cutting speed (800, 1000 and $1200 \mathrm{rpm})$, feed rate $(0.1,0.2$ and $0.3 \mathrm{~mm})$ and depth of cut $(0.4,0.8$ and $1.2 \mathrm{~mm})$ in comparison with nanofluid with $\mathrm{Al}_{2} \mathrm{O}_{3}$ and $\mathrm{MoS}_{2}$. This is because of the covalent structure in graphite atomic structure was bigger that promotes a better rolling effect. Gutnichenko et al. [8] investigated machining performance through turning process of Alloy 718 with micro-grain coated cutting tools under MQL condition using nanofluid from commercial vegetable oils from rapeseed with the addition of $0.2 \%$ (vol.) of the graphite nanoplatelets (GnP). Based on the results, GnP nanofluids showed better machining performance through MQL such as tool life, process stability and surface finish of the workpiece. Moreover, it also observed that the applied of $\mathrm{GnP}$ nanofluids had decreased the friction in the contact surface of the cutting zone compare to the pure oil lubrication.

Therefore, the current study focuses to develop a new formulation of bio-based MWF from vegetable oils with the inclusion of green solid additives to enhance the tribological performance outcomes. Modified jatropha oils (MJOs) is selected as highly potential metalworking fluids which more sustainable primarily for the process of the machining. The effectiveness of the nanoparticles additives namely hBN and graphene nanoparticles was evaluated at various concentration. Subsequently, tribological performance of MJOs with minimum concentration of hBN and graphene nanoparticles was evaluated via four ball tribo test to determine the potential of the newly development of metalworking fluids.

\section{EXPERIMENTAL PROCEDURE}

\section{A. Preparation of bio-based nanofluids for lubrication}

In the present study, the crude jatropha oil (CJO) was undergo chemical alteration and added with additives in nano-sized particle to improve the performance of the lubricant in terms of thermal-oxidative stability of the oil. Firstly, CJO was undergo the chemical modification through two-step acid-based catalyst to obtain the jatropha methyl ester (JME). The first step involved esterification process in which aimed to reduce the content of fatty acids (FFA) until less than $1 \%$ to achieve high yield of JME. The second step is the transesterification of the methanol and esterified jatropha oil $\left(\mathrm{CH}_{4} \mathrm{O}: \mathrm{EJO}\right)$ at ratio of 6:1 to produce JME. Next, the process of transesterification was performed involved chemical reaction between JME with TMP at molar ratio of
3.5:1 and the presence of presence of 1\% (wt./wt.) sodium methoxide $\left(\mathrm{NaOCH}_{3}\right)$ to develop TMP triester or noted as modified jatropha oil (MJO). The MJO was blended with hBN and graphene nanoparticles at temperature of $60^{\circ} \mathrm{C}$ and $750 \mathrm{rpm}$ for about 30 minutes [9]. Table I indicates all the lubricant samples prepared with nanoparticles additives.

Table- I: Detail of MJO samples

\begin{tabular}{|c|c|c|}
\hline $\begin{array}{l}\text { Name of } \\
\text { Sample }\end{array}$ & $\begin{array}{c}\text { Concentration of } \\
\text { Additives (Wt. \%) }\end{array}$ & $\begin{array}{c}\text { Types of Nanoparticles } \\
\text { Additives }\end{array}$ \\
\hline MJOh1 & 0.01 & \multirow{2}{*}{ hBN } \\
\hline MJOh2 & 0.025 & \\
\hline MJOh3 & 0.05 & \\
\hline MJOg1 & 0.01 & Graphene \\
\hline MJOg2 & 0.025 & \\
\hline MJOg3 & 0.05 & \\
\hline
\end{tabular}

\section{B. Physical analyses}

The physical testing of the modified jatropha oils such as kinematic viscosity, viscosity index and flash point are carried out by following the procedure of American Society for Testing and Materials (ASTM) standard and compared with the synthetic ester (SE), Unicut Jinen MQL which commercially available in the market as the benchmark oil. The value of the kinematic viscosity of the oil samples were measured and recorded at the different temperature from $30^{\circ} \mathrm{C}$ to $100^{\circ} \mathrm{C}$ according to the ASTM D445 by using a portable viscometer. The oil sample was heated uniformly until reached the desired temperature and then, immerse the solid stainless-steel sensor of the viscometer into the oil sample. Furthermore, standard ASTM D2270 was applied to calculate the viscosity index of the oil samples using the result value of the kinematic viscosity which obtained at both $40^{\circ} \mathrm{C}$ and $100^{\circ} \mathrm{C}$. Standard procedure of ASTM D93 was followed for the flash point test by using Pensky-Martens closed cup tester at which the sample of oil was heated and stirred in the container at specified rates.

\section{Tribological testing}

Tribological study of the MWF is related on friction and wear mechanisms. In this study, DUCOM four-ball tribotester was used to conduct tribology test according to the standard procedure of ASTM D4172 [10]. The material of ball used for this testing is a $12.7 \mathrm{~mm}$ diameter of the chrome steel ball (AISI 52100) with 64 to 66 HRC of hardness. In this testing, the three steel ball which in the stationary condition was placed on the lower ball pot assembly and secured with the locking ring and nut while the rotating ball was held and locked at the upper spindle. Approximately about $10 \mathrm{ml}$ of the lubricant sample was filled into the ball pot for each of testing. Then, the ball pot was placed into the machine and applied the normal load ( $392 \pm 2 \mathrm{~N}$ ) gradually to prevent form any concentrated stress. The constant speed of $1200 \mathrm{rpm}$ was set and applied to the machine to rotate the upper rotating ball for 60 minutes when the set temperature $\left(75^{\circ} \mathrm{C}\right)$ is reached. The setup of the four-ball test was displayed in Fig. 1.

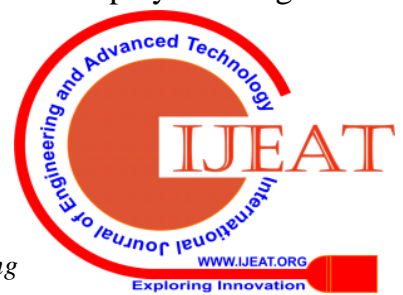


The COF value was determined automatically based on the data of the friction torque that recorded by the software of Winducom 2010. The morphology of worn surfaces after the four-ball test was analyzed and captured by using scanning electron microscope (SEM). Lastly, the surface roughness of the worn surfaces on the steel ball was determined using surface roughness tester according to ISO4288:1996.

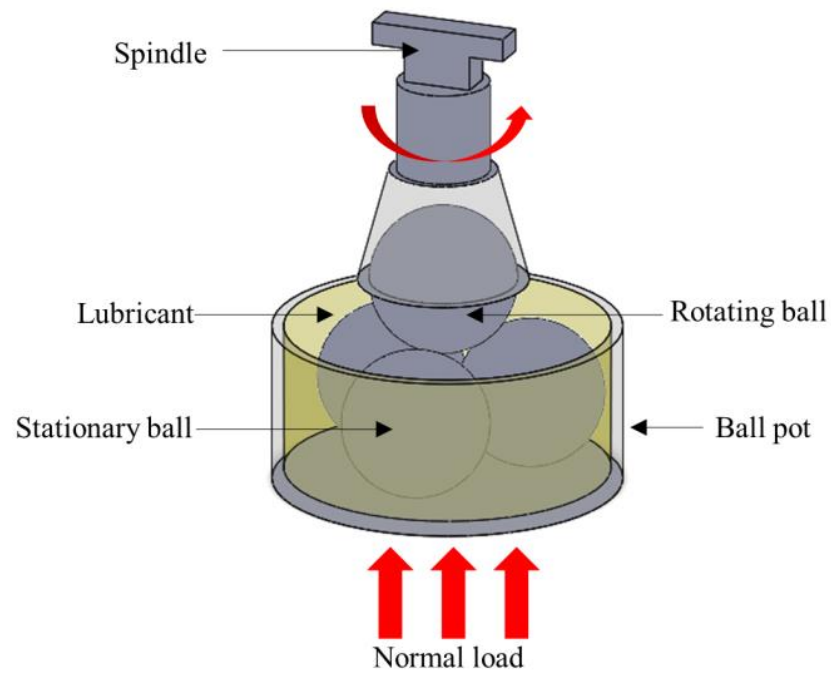

Fig. 1: Set up for four ball tribo test

\section{RESULT AND DISCUSSION}

\section{A. Physical properties of bio based nanofluids}

Viscosity of MWF is an important measurement that indicates the resistance of flow and influenced the lubrication film that formed between the contact surfaces to provide better prevention towards friction and wear. It can be proven that there are significant decreases in kinematic viscosity influenced by the increase of the temperature of the sample of lubricant as shown in Fig. 2. This phenomenon was occurred because the motion of the molecules in the lubricant samples were moved faster when the temperature is higher. In the study of Singh et al. [11], the author initiated that the changes of the viscosity at different temperature was reflected on the decrease in density of the lubricants. The result in Fig. 2 indicated that the SE had highest value of kinematic viscosity within the range of 30 to $100^{\circ} \mathrm{C}$ compared to MJO samples. This result indicated the viscosity of the oil become lower due to the weaken intermolecular forces on the hydrogen bonding that caused by the chemical modification via transesterification reaction undergo by MJO [12].

Recent study by Chhibber et al. [13] emphasized that it is undesirable having higher viscosity in mechanisms of the lubrication as it can creates problems on increasing energy consumption and might fail at the lower temperature. The value of viscosity should be optimum at any application as the low viscosity possess more wear while high viscosity provided critical frictional loss [14]. Furthermore, the value of kinematic viscosity of lubricant samples was slightly increased as the concentration of hBN and graphene nanoparticle additives is higher.

Fig. 3 demonstrates the result of the viscosity index of the SE and MJO samples. The viscosity index of MJO samples was higher compared to SE. This is because of the chemical modification that performed to the crude jatropha oil to produce the MJO. MJOg3 provided highest viscosity index which influenced by the highest value of kinematic viscosity at $100^{\circ} \mathrm{C}\left(5.23 \mathrm{~mm}^{2} / \mathrm{s}\right)$ among the other samples. The result was proven that the negative coefficient of thermal expansion of graphene $\left(-8 \times 10^{-6} /{ }^{\circ} \mathrm{C}\right)$ effected the high viscosity index of the MJOs with graphene compared to hBN [15]. Meanwhile, the MJOh3 recorded as second highest of viscosity index as it also has lower coefficient of thermal expansion $\left(1 \times 10^{-6} /{ }^{\circ} \mathrm{C}\right)$.

Table- II: Kinematic viscosity of the lubricant samples

\begin{tabular}{|c|c|c|c|c|c|}
\hline \multirow{2}{*}{ Sample } & \multicolumn{5}{|c|}{ Kinematic Viscosity } \\
\cline { 2 - 6 } & $\mathbf{3 0}^{\circ} \mathbf{C}$ & $\mathbf{4 0}^{\circ} \mathbf{C}$ & $\mathbf{6 0}^{\circ} \mathbf{C}$ & $\mathbf{8 0}^{\circ} \mathbf{C}$ & $\mathbf{1 0 0}^{\circ} \mathbf{C}$ \\
\hline SE & 31.12 & 19.12 & 12.46 & 7.56 & 4.32 \\
\hline MJOh1 & 18.73 & 15.34 & 9.75 & 4.71 & 4.56 \\
\hline MJOh2 & 18.93 & 15.55 & 10.14 & 4.93 & 4.67 \\
\hline MJOh3 & 19.21 & 15.96 & 10.34 & 5.15 & 4.89 \\
\hline MJOg1 & 18.94 & 16.82 & 9.90 & 4.94 & 4.79 \\
\hline MJOg2 & 19.23 & 17.16 & 10.46 & 5.26 & 5.01 \\
\hline MJOg3 & 19.52 & 17.38 & 10.79 & 5.48 & 5.23 \\
\hline
\end{tabular}

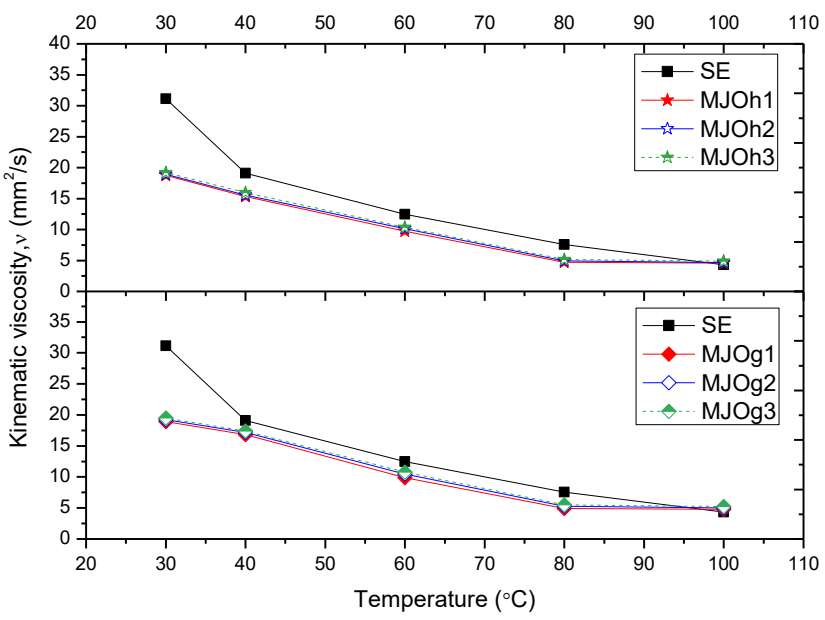

Fig. 2: The kinematic viscosity at 30 to $100^{\circ} \mathrm{C}$ of the sample of lubricant

Table- III: Kinematic viscosity and viscosity index of sample lubricants

\begin{tabular}{|c|c|c|}
\hline Sample & Viscosity Index & Flash Point $\left({ }^{\circ} \mathrm{C}\right)$ \\
\hline SE & 137 & 250 \\
\hline MJOh1 & 242 & 220 \\
\hline MJOh2 & 250 & 222 \\
\hline MJOh3 & 267 & 224 \\
\hline MJOg1 & 233 & 222 \\
\hline MJOg2 & 250 & 220 \\
\hline MJOg3 & 269 & 230 \\
\hline
\end{tabular}

Published By: 


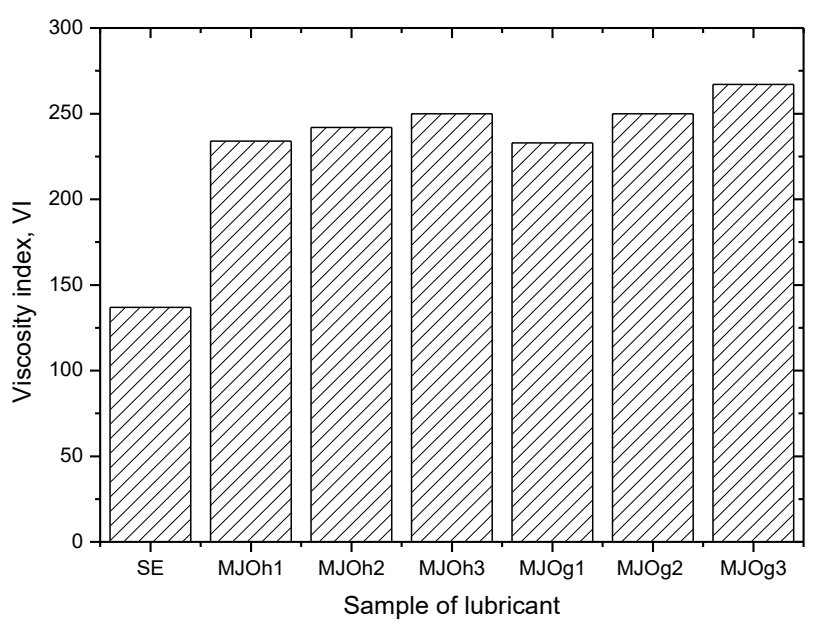

Fig. 3: Variation of viscosity index of the lubricant samples

Flash point indicates the lowest temperature of the oil samples at which it can vaporize when in contact with air, hence the inflammation can be produced by providing an energy external trigger. Fig. 4 displays that highest value of flash point was recorded by SE with $250^{\circ} \mathrm{C}$ compared to the MJO samples. The MJO samples were contributed lower flash point than SE because

of the presence of the unreacted JME during transesterification process that involved reaction between JME and TMP in the development of TMP ester or known as modified oil [16]. It also can be seen that there is a minimal increment of the flash point as the concentration of hBN and graphene nanoparticles increasing. The higher flash point of the lubricant indicated that it is low in term of vapour pressure and volatility that significantly provided low potential fire hazards during the use of the lubricant[17].

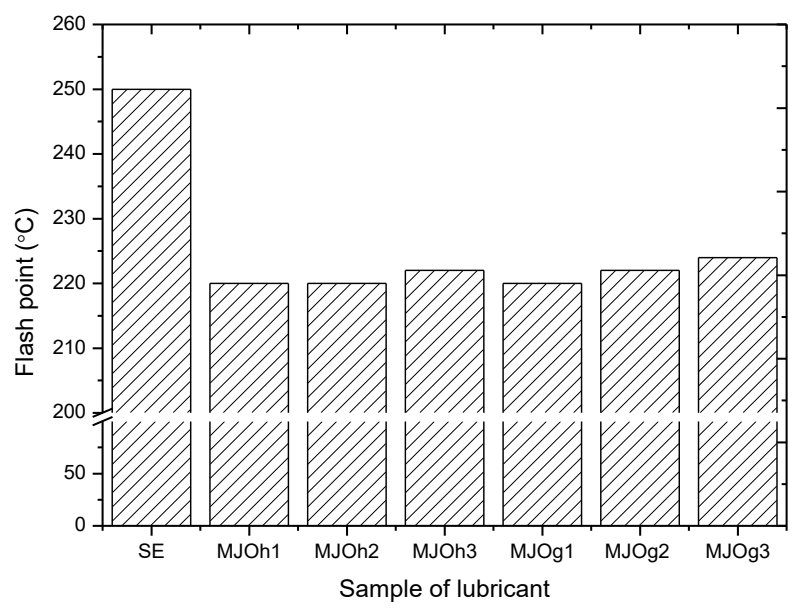

Fig. 4: Variation of flash point of the lubricant samples

\section{B. Tribological results}

Fig. 5 presents the result of coefficient of friction (COF) for SE and MJOs samples. The highest value of COF was recorded by SE with value of 0.0894 compared to the MJOs sample. The improvement of COF in range of $22-62 \%$ was obtained by the sample of MJOs compared to SE as the molecular chains were formed in the MJOs caused the reduction of friction on the contact surface. These results had shown the advantage of inclusion of nanoparticles because it can filled the inter-asperity valleys, thus formed thin transfer films that lead to effective lubrication [18]. MJOg2 offers better performance because had the lowest COF of 0.0332 which improved more than $62 \%$ compared to SE. The graphene nanoparticles has two-dimensional structure which the particles were ease to slide slide between the two mating surfaces, thus improved in term of friction. Nevertheless, the inclusion at higher concentration of graphene in MJOg3 causes some coagulation that promoting the poor frictional properties due to the unstable friction as well as exhibited vibration in the friction zone [19]. Furthermore, the trend of COF for MJO blended with hBN was a bit differ from graphene nanofluids as the lowest concentration (0.01 wt.\%) at MJOh1 has recorded the lowest COF of 0.0509 compared with MJOh2 and MJOh3. This is because the high concentration of hBN acts as abrasive particles which might damage the worn surface due to plastic deformation [20].

\section{Table- IV: Coefficient of friction for all sample lubricants}

\begin{tabular}{|c|c|}
\hline Sample & Coefficient of friction \\
\hline SE & 0.0894 \\
\hline MJOh1 & 0.0509 \\
\hline MJOh2 & 0.0570 \\
\hline MJOh3 & 0.0695 \\
\hline MJOg1 & 0.0414 \\
\hline MJOg2 & 0.0332 \\
\hline MJOg3 & 0.0454 \\
\hline
\end{tabular}

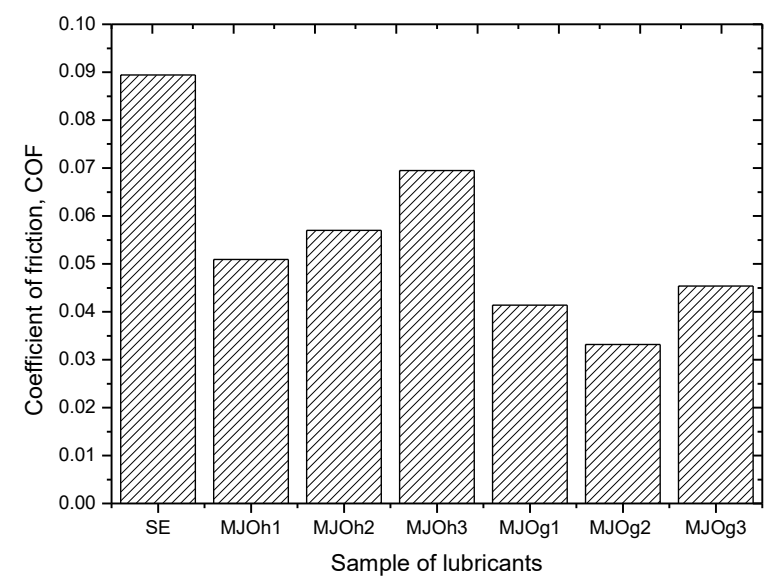

Fig. 5: The coefficient of friction of the lubricant samples

Fig. 6 shows the morphology of worn surfaces for lubricant samples of SE and MJOs. It was observed that the SE had parallel deep groove that form on the worn surface. The worn surfaces of SE has severely abrasive wear which indicated that the lubrication film was completely broken. The presence of nanoparticles provided smooth worn surface with a few of groove and material transfer spotted compared to SE. The deep groove on the worn surfaces was developed due to the removal of the thin layer soap film which initially formed by the fatty acid chain during lubrication [21].

Published By:

Blue Eyes Intelligence Engineering 

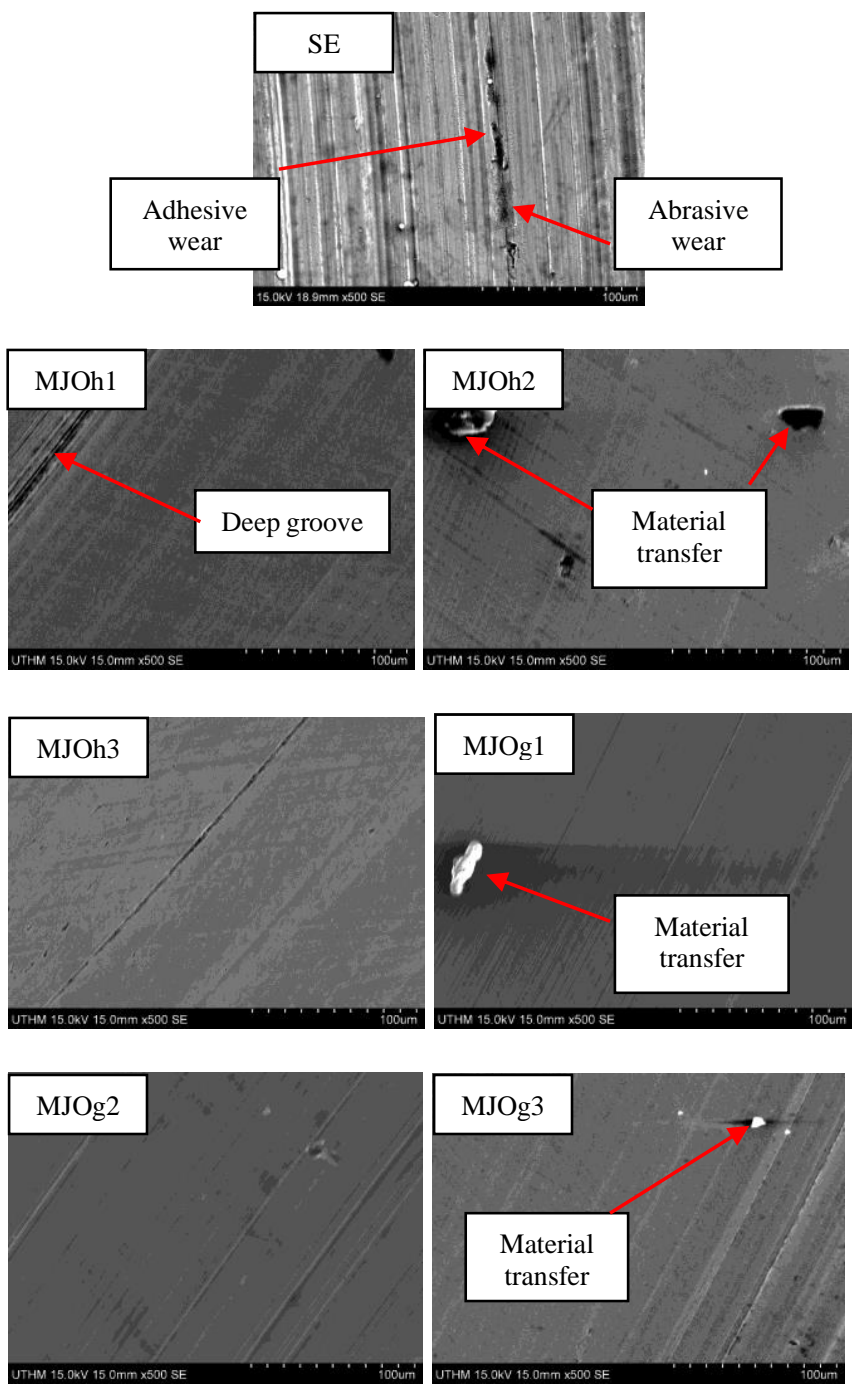

Fig. 6: SEM morphology of the worn surface on the steel ball at magnification of $500 x$

Fig. 7 indicated the variation of surface roughness of the all the lubricant samples. The measurement of surface roughness was performed to observe and comprehend on the steel ball that had worn out after the four-ball test. From the result obtained, the surface roughness of SE was highest at $0.306 \mu \mathrm{m}$ compared to the MJOs sample. This proven that the SE provided a poor lubrication film as the worn surface produce was rough comparing to the other MJOs sample. The presence of the hBN and graphene nanoparticles in MJO was improved the surface roughness with 29 to 35\% lower compared to SE. The inclusion of the 0.05 wt.\% hBN and graphene nanoparticles in MJO which represent by MJOh3 and MJOg3 provided the lowest surface roughness of $0.199 \mu \mathrm{m}$ and $0.205 \mu \mathrm{m}$ respectively. This proven that the nanoparticles additives play role in decrease of wear by filling the asperities between the contact surfaces, hence produced a superior protective transfer film. The lowest concentration of nanoparticles additives was considered not sufficient to protect from wear, therefore produce a high surface roughness [22].
Table- V: Surface roughness of the lubricant samples

\begin{tabular}{|c|c|}
\hline Sample & Surface Roughness \\
\hline SE & 0.306 \\
\hline MJOh1 & 0.209 \\
\hline MJOh2 & 0.207 \\
\hline MJOh3 & 0.199 \\
\hline MJOg1 & 0.217 \\
\hline MJOg2 & 0.214 \\
\hline MJOg3 & 0.205 \\
\hline
\end{tabular}

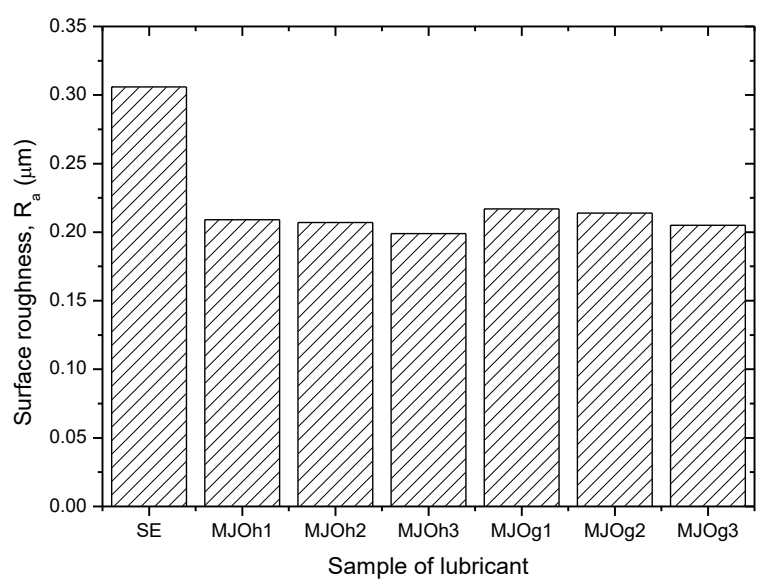

Fig. 7: Variation of surface roughness of the lubricant samples

\section{CONCLUSION}

In general, the present study was performed physicochemical properties and tribological tests to assess the relative performance for all sample of lubricant as a sustainable lubricant by comparing the result with commercial SE. The following conclusions are drawn from this experimental study:

a) The chemical modification and the inclusion of $\mathrm{hBN}$ and graphene nanoparticles in MJO based oil additives had showed a significant improvement on the physicochemical properties. MJO with 0.05 wt.\% of hBN and graphene nanoparticles (MJOh3 and MJOg3) provided the highest VI of 267 and 269 respectively. The viscosity of the lubricant can be proved affect the performance of the lubricant as it influences the thickness of lubrication film.

b) MJOg2 had an optimum concentration which provided the lowest coefficient of friction (0.0332) among other samples. However, it does not provide the enough wear protection since the surface roughness of the worn surface was high compared to MJOh3. It can be concluded that, in MJOh3 provided smoother of worn surfaces by providing $34.96 \%$ improvement of surface roughness value even though the coefficient of friction was the highest among the MJOs sample but lower than SE.

c) The addition of the nanoparticles in the based oil is remarkable as excellent lubrication performances because of the deposition of nanoparticles additives in the rubbing surfaces which filling the asperities between the contact surfaces, hence produced a superior protective transfer film.

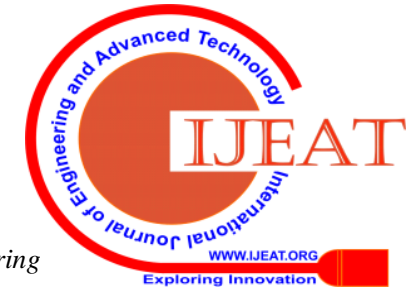


Based on the overall result, the addition of nanoparticles additives has promoted improvement on tribological characteristic and highly suitable as substitution of SE.

\section{ACKNOWLEDGMENT}

The authors gratefully acknowledge with thanks to Ministry of Education Malaysia (MOE) for financial assistance of this experimental work through the medium of the TIER 1 Research Grant (H176) and Fundamental Research Grant Scheme Vot No. FRGS/1/2018/TK03/UTHM/03/10 and partially funded by Universiti Tun Hussein Onn Malaysia (UTHM).

\section{REFERENCES}

1. J. McNutt and Q. S. He, "Development of biolubricants from vegetable oils via chemical modification,” J. Ind. Eng. Chem., vol. 36, pp. 1-12, 2016.

2. M. A. Jabbar, U. Tunku, A. Rahman, Z. Hashim, H. Zainuddin, and M. D. Task, "Metalworking Fluid Exposure and Consequences on Skin Health in a Metal Machining Factory: Review Article," no. April, 2018.

3. M. C. de Souza, J. F. de S. Gonçalves, S. Y. S. Lutif, and J. de O. Gomes, "Tribological evaluation of the Jatropha and Tung-based oils as bio-lubricants on Al-7050-T7451 alloy," J. Brazilian Soc. Mech. Sci. Eng., vol. 41, no. 6, pp. 1-11, 2019.

4. N. Talib, H. Sasahara, and E. A. Rahim, "Evaluation of modified jatropha-based oil with hexagonal boron nitride particle as a biolubricant in orthogonal cutting process," Int. J. Adv. Manuf. Technol., vol. 92, no. 1-4, pp. 371-391, 2017.

5. Y. M. Ã. Shashidhara and S. R. Jayaram, "Vegetable oils as a potential cutting fluid — An evolution," Tribiology Int., vol. 43, no. 5-6, pp. 1073-1081, 2010.

6. A. Kashyap and A. P. Harsha, "Tribological studies on chemically modified rapeseed oil with $\mathrm{CuO}$ and $\mathrm{CeO} 2$ nanoparticles," Proc. Inst. Mech. Eng. Part J J. Eng. Tribol., vol. 230, no. 12, pp. 1562-1571, 2016.

7. M. K. Gupta et al., "Performance Evaluation of Vegetable Oil-Based Nano-Cutting Fluids in Environmentally Friendly Machining of Inconel-800 Alloy," Materials (Basel)., vol. 12, no. 17, p. 2792, 2019.

8. O. Gutnichenko, V. Bushlya, S. Bihagen, and J. E. Ståhl, "Influence of $\mathrm{GnP}$ additive to vegetable oil on machining performance when MQL-assisted turning Alloy 718," Procedia Manuf., vol. 25, pp. 330-337, 2018.

9. N. Talib, R. Md. Nasir, and E. Abd. Rahim, "Investigation on the Tribological Behaviour of Modified Jatropha Oil with Hexagonal Boron Nitride Particles as a Metalworking Fluid for Machining Process,” Int. J. Integr. Eng., vol. 10, no. 3, pp. 57-62, 2018.

10. ASTM D4172, "Standard Test Method for Wear Preventive Characteristics of Lubricating Fluid (Four-ball Method)," in Annu. B. ASTM Stand, West Conshohocken, PA, 2010.

11. N. Singh, Y. Singh, A. Sharma, and A. Singla, "Effect of addition of copper nanoparticles on the tribological behavior of macadamia oil at different sliding speeds," Energy Sources, Part A Recover. Util. Environ. Eff., vol. 41, no. 23, pp. 2917-2928, 2019.

12. C. Y. Onuh, A. Dosunmu, P. A. L. Anawe, V. Efeovbokhan, and A. Adebisi, "Transesterification of non-edible vegetable oil for lubricant applications in water-based mud: A review,” Int. J. Appl. Eng. Res., vol. 12, no. 18, pp. 7397-7401, 2017.

13. V. K. Chhibber, M. Sanket, and K. Saxena, "Comparative Study -A Mineral Oil Based Lubricant and Lubricant Obtained From Vegetable Oil,” Int. J. Nov. Res. Interdiscip. Stud., vol. 2, no. 4, pp. 1-7, 2015.

14. S. Rani, M. L. Joy, and K. P. Nair, "Evaluation of physiochemical and tribological properties of rice bran oil - Biodegradable and potential base stoke for industrial lubricants," Ind. Crops Prod., vol. 65, pp. 328-333, 2015.

15. D. Yoon, Y. Son, and H. Cheong, "Negative Thermal Expansion Coefficient of Graphene Measured by Raman Spectroscopy," Nano Lett., vol. 11, no. 8, pp. 3227-3231, 2011.

16. N. Talib and E. A. Rahim, "Experimental evaluation of physicochemical properties and tapping torque of hexagonal boron nitride in modified jatropha oils-based as sustainable metalworking fluids," J. Clean. Prod., vol. 171, pp. 743-755, 2017.

17. N. A. Zainal, N. W. M. Zulki, M. Gulzar, and H. H. Masjuki, “A review on the chemistry , production , and technological potential of biobased lubricants," Renew. Sustain. Energy Rev., vol. 82, no. June
2017, pp. 80-102, 2018.

18. C. J. Reeves, P. L. Menezes, M. R. Lovell, and T. C. Jen, "The size effect of boron nitride particles on the tribological performance of biolubricants for energy conservation and sustainability," Tribol. Lett., vol. 51, no. 3, pp. 437-452, 2013.

19. T. Lv, S. Huang, E. Liu, Y. Ma, and X. Xu, "Tribological and machining characteristics of an electrostatic minimum quantity lubrication (EMQL) technology using graphene nano-lubricants as cutting fluids,” J. Manuf. Process., vol. 34, pp. 225-237, 2018.

20. N. Talib, R. M. Nasir, and E. A. Rahim, "Tribological behaviour of modified jatropha oil by mixing hexagonal boron nitride nanoparticles as a bio-based lubricant for machining processes," J. Clean. Prod., vol. 147, pp. 360-378, 2017.

21. P. Zulhanafi, S. Syahrullail, and M. M. Faridzuan, "Tribological performance of palm kernel oil added with nanoparticle copper oxide using fourball tribotester," J. Teknol., vol. 79, no. 7-4, pp. 53-59, 2017.

22. J. M. Liñeira del Río et al., "Tribological and Thermophysical Properties of Environmentally-Friendly Lubricants Based on Trimethylolpropane Trioleate with Hexagonal Boron Nitride Nanoparticles as an Additive," Coatings, vol. 9, no. 8, p. 509, 2019.

\section{AUTHORS PROFILE}

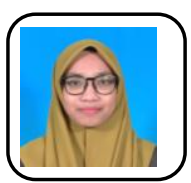

Nor Athira Jamaluddin has received her Diploma in Mechanical Engineering and Bachelor Degree in Mechanical with Honours from Universiti Tun Hussein Onn Malaysia (UTHM). She is pursuing her Master in Mechanical Engineering at UTHM. Her research is mainly focused on the performance of vegetable based nanofluids in term of their tribology study and machining evaluation as metalworking fluids for machining process.

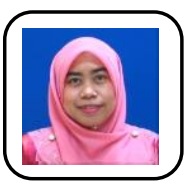

Norfazillah Talib has earned her PhD in Mechanical Engineering from Universiti Tun Hussein Onn Malaysia (UTHM) and currently as a senior lecturer in Faculty of Mechanical and Manufacturing Engineering at UTHM. Her research interests related to the field of tribology study and sustainable manufacturing.

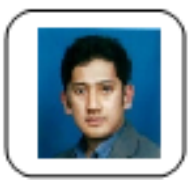

Amiril Sahab Abdul Sani received his $\mathrm{PhD}$ in Mechanical engineering from Universiti Tun Hussein Onn Malaysia (UTHM). He was hired by Universiti Malaysia Pahang (UMP) as a senior lecturer in Faculty of Manufacturing Engineering. His research interests related to sustainable manufacturing, macro \& micro machining and tribology study. 